\title{
A modalidade deôntica na construção completiva impessoal com matriz ser + preciso: uma análise cognitivo-funcional
}

\author{
Dayane Alves Wiedemer \\ Universidade do Estado do Rio de Janeiro (UERJ), Rio de Janeiro, Brasil \\ daywiedemer@outlook.com
}

DOI: http://dx.doi.org/10.21165/el.v45i1.775

\begin{abstract}
Resumo
A partir dos pressupostos do Funcionalismo norte-americano e da Linguística Cognitiva, apresentamos os resultados da análise da construção completiva impessoal composta por matriz com verbo ser + preciso, e os diferentes graus da modalidade deôntica (obrigação externa, obrigação interna e necessidade). Para compor os corpora de análise, utilizamos dados extraídos dos jornais Folha de São Paulo e O Globo. Quanto aos resultados, observamos que há predominância da posição da oração matriz à esquerda, marcando a atitude do falante. Vimos que há maior uso da obrigação externa, seguida da necessidade e, por fim, um menor uso da obrigação interna. Quanto aos tipos de verbo da oração completiva, na obrigação externa há um maior uso de verbos dinâmicos; na obrigação interna prevalece o uso de verbos cognitivos ou epistêmicos; e, na necessidade, há ocorrências de verbos tanto dinâmicos quanto cognitivos.
\end{abstract}

Palavras-chave: funcionalismo; modalidade deôntica; oração completiva; impessoalidade.

\section{The Deontic Modality in Impersonal Completive Constructions Composed of a Matrix Clause with ser + preciso: a Cognitive-Functional Analysis}

\begin{abstract}
From the assumptions of the American Functionalism and Cognitive Linguistics, this paper presents the results of an analysis about impersonal completive constructions composed of a matrix clause with the verb ser + preciso, and the different degrees of the deontic modality (external obligation, internal obligation and necessity). To compose the corpora for analysis, data extracted from the newspapers Folha de São Paulo and $O$ Globo were extracted. As for the results, it was noticed that the matrix clause is predominantly positioned on the left of a construction, which indicates the speaker's attitude. In addition, there is a greater use of external obligation, then necessity and, finally, a less use of internal obligation. As for the types of verbs in completive constructions, dynamic verbs are most used in external obligation; cognitive or epistemic verbs are predominant in internal obligation; and both dynamic and cognitive verbs occur in necessity.
\end{abstract}

Keywords: functionalism; deontic modality; completive construction; impersonality.

\section{Introdução}

Este artigo tem por objetivo apresentar os resultados da pesquisa ${ }^{1}$ feita acerca da construção completiva impessoal com verbo ser + preciso, que é constituída de uma oração matriz (ser [conjugado na $3^{a}$ pessoa do singular] + preciso) + uma oração completiva com função de sujeito sintático, conforme exemplificado em (01) e (02).

\footnotetext{
1 Os resultados aqui apresentados são oriundos da minha monografia de graduação em Letras da Universidade Federal Fluminense (2014).
} 

consensual a opinião de que, além dessas iniciativas, é preciso haver uma gestão eficiente de ocupacão territorial. Trata-se de organizar a cidade de forma mais compacta, reduzindo a distância entre casa, comércio e trabalho, sem descuidar de ciclovias e calçadas amplas.

(Folha de São Paulo, outubro 2013)2

(02) Estavam no grupo pessoas de dinheiro, é claro, preocupadas, por exemplo, com o imposto sobre grandes fortunas. Aliás, perguntaram ao governador e adoraram a resposta. Campos disse: há impostos demais no Brasil. É preciso reduzi-los e torná-los mais progressivos; ricos devem pagar mais, mas não se pode esfolar o investidor e a empresa.

$(\text { O Globo, outubro 2013) })^{3}$

A oração matriz com ser + preciso é uma estrutura linguística relacionada à modalidade deôntica, que se encontra no eixo da conduta e expressa os valores de obrigação, podendo ser moral, interna e ditada pela consciência ou obrigação material, externa, social e ditada pelas circunstâncias (ALMEIDA, 1980; NEVES, 1996), além do valor de necessidade. Embora haja sujeito oracional expresso, depreende-se a leitura do matiz semântico impessoal da estrutura predicadora, alçada à posição inicial da construção. Com esse recurso, contrasta-se a informação da construção completiva impessoal com o entorno discursivo (em $1^{\mathrm{a}} \mathrm{e} 3^{\mathrm{a}}$ pessoas do plural), minimizando a própria participação no evento, descomprometendo-se da informação veiculada (NEVES, 1996; DIAS, 2013a, 2013b).

Observar os diferentes usos dos graus de modalidade implica analisar como o falante emprega determinado recurso para marcar a impessoalidade em seu discurso, a fim de se distanciar, para não se comprometer com as informações veiculadas, seja, por um lado, em caráter predominantemente obrigatório, e, por outro lado, predominantemente necessário.

Para compor os corpora de análise, selecionamos os jornais O Globo e Folha de São Paulo, ambos na seção "Opinião", e disponíveis em seus acervos on-line, respectivamente, $<$ http $/ /$ oglobo.globo.com/opiniao/>

$<$ http $/ /$ www1.folha.uol.com.br/opiniao/>, e coletamos dados dos meses de setembro e outubro de 2013. A escolha dos jornais se deve à linguagem formal utilizada, pois percebemos que, quanto mais informal for a situação de fala, menor será o uso da construção completiva subjetiva. A escolha da seção "Opinião" se deve ao fato de que, em outros gêneros e seções, não foram encontrados dados significativos para avaliação.

$\mathrm{Na}$ análise qualitativa, consideramos as realizações sintáticas, semânticas e pragmáticas que puderam justificar o uso da sentença complexa, bem como permitiu-nos justificar o uso da modalidade deôntica, verificando seus graus e observando se há restrições quanto ao gênero textual. Na análise quantitativa, consideramos a contagem feita por frequência simples, como recurso sistemático para que todos os fenômenos pudessem ser testados de maneira análoga.

Para a avaliação das ocorrências, consideramos os seguintes elementos: (i) a ocorrência do predicador (é preciso) na oração matriz; (ii) valor semântico-pragmático da

\footnotetext{
2 Disponível em: <http://www1.folha.uol.com.br/opiniao/2013/10/1355589-editorial-mais mobilidade.shtml>

3 Dis ponível em: 〈http://oglobo.globo.com/opiniao/entre-mercado-o-social-10314938>

${ }^{4}$ Bräkling (2000) define o artigo de opinião como um gênero que propicia a busca pelo convencimento do outro sobre alguma ideia. Dessa forma, há a tentativa de influenciá-lo e transformar seus valores a favor, seja refutando, seja atestando, uma posição.
} 
oração matriz (obrigação interna, obrigação externa, necessidade); e (iii) tipo semântico de verbo (dicendi, dinâmico, cognitivo, implicativo,) da oração completiva subjetiva.

Delimitamos, como hipóteses, alguns pontos considerados essenciais na compreensão do assunto: (i) a posição da oração matriz à esquerda marcaria mais a atitude do falante; (ii) o uso da construção é preciso caracterizaria a impessoalidade em relação ao entorno discursivo; (iii) os valores de obrigação (interna ou externa) e necessidade seriam variáveis de acordo com a completiva subjetiva; (iv) o tipo de verbo da oração completiva teria relação com o grau da modalidade expresso na construção.

O presente artigo se organiza da seguinte forma: (i) na primeira seção, apresentamos a fundamentação teórica basilar desta pesquisa; (ii) na segunda seção, é feita uma breve revisão sobre os conceitos de modalidade; (iii) na terceira seção, a noção de construção impessoal é discutida a partir da perspectiva cognitiva; (iv) na quarta seção, examinamos os resultados e interpretamos as hipóteses investigadas; (v) na quinta seção, tem-se as considerações finais, e, por fim, nossas referências bibliográficas.

\section{O Funcionalismo norte-americano e a Linguística Cognitiva}

O Funcionalismo Norte-Americano é uma corrente teórica que estuda a relação entre a estrutura gramatical das línguas e os diferentes contextos comunicativos em que elas podem ser usadas, ou seja, há uma vinculação entre discurso e gramática. A proposta, então, é a de que esse estudo seja feito simultaneamente para que seja possível entender como a língua se configura (CUNHA; BISPO; SILVA, 2013).

Givón (1979) sustenta que a linguagem evolui do âmbito pragmático para o âmbito da gramática, ou seja, a gramática tem sua origem no discurso, entendido como um conjunto de estratégias empregadas pelo usuário da língua para organizar, de modo funcional, o seu texto para um determinado ouvinte em alguma situação comunicativa, seja oral ou escrita.

Nesse modelo, a gramática é vista como um sistema aberto, fortemente suscetível à mudança e intensamente afetado pelo uso que the é dado no dia a dia, sendo assim, a gramática é o anexo maleável e internalizado das formações vindas da língua em uso, do discurso e das situações interacionais acumuladas pelos indivíduos no decorrer da vida. Devido a isso, o Funcionalismo explicará a organização dessa gramática e as suas estratégias com base nos princípios cognitivos e comunicativos (CUNHA; TAVARES, 2007).

As autoras (op. cit.) entendem que, se a gramática é constituída em contextos específicos de uso da língua, para compreendê-la temos que levar em conta a perspectiva discursivo-textual; assim, será possível explicar a forma da língua a partir das funções que ela desempenha na comunicação.

A Linguística Cognitiva vê o comportamento linguístico como reflexo de capacidades cognitivas que dizem respeito à experiência humana no contexto de suas atividades individuais, sociointeracionais ou culturais. Dessa forma, as construções linguísticas são concebidas como esquemas cognitivos padrões usados para desempenhar outras atividades, ou seja, são procedimentos parcialmente automatizados utilizados para produzir comunicação. O falante, então, adquire o conhecimento ao passo em que aprende 
a usar a sua língua. Posto isso, assume-se que as categorias linguísticas são assentadas na experiência que temos das construções em que ocorrem.

Silva (1997), ao expor a teoria, afirma que a Linguística Cognitiva é uma abordagem da linguagem perspectivada como meio de conhecimento e em conexão com a experiência humana do mundo e que ela rejeita os pressupostos da autonomia da linguagem, como a separação entre o conhecimento semântico e o conhecimento extralinguístico. Além disso, por atribuir grande importância ao caráter funcional dos fenômenos linguísticos e por desenvolver uma análise baseada no uso, é uma linguística pragmaticamente orientada, sintonizada, portanto, com a linguística funcional.

Sobre a união das duas teorias, que resultam na abordagem mais recente da Linguística Cognitivo-Funcional, Cunha, Bispo e Silva (2013) afirmam que as duas correntes compartilham vários pressupostos teórico-metodológicos, como a rejeição à autonomia da sintaxe, a incorporação da semântica e da pragmática às análises, entre outros. A gramática, então, passa a ser vista como representação cognitiva da experiência dos indivíduos com a língua e, portanto, pode ser afetada pelo uso linguístico.

\section{A modalidade: breve revisão}

As modalidades baseiam-se em modelos lógicos, porém diferenciam-se deles por suas formas não contínuas que assumem as línguas. Os modelos lógicos são baseados principalmente em dois eixos básicos, o de conhecimento e o de conduta, que são pertinentes às funções linguísticas e de modalidade.

De modo geral, "a modalidade pode ser definida como o modo pelo qual o significado de uma frase é qualificado de forma a refletir o julgamento do falante sobre a probabilidade de ser verdadeira a proposição por ele expressa" (QUIRK, 1985 apud NEVES, 1996, p. 164), assim, podemos definir a modalidade como a avaliação do falante acerca daquilo que se é dito.

Em termos gerais, a noção de modalidade resulta em uma análise semântica do enunciado que permite, assim, distinguir o dictum, entendido como conteúdo proposicional, e o modus, entendido como a própria modalidade, o ponto de vista do falante sobre aquilo que é dito. Em outras palavras, isso equivale a dizer que, ao lado daquilo que se diz (o dictum), há o modo (modus) como aquilo que se diz é dito.

A modalidade manifesta-se por meio de verbos, advérbios, substantivos, categorias gramaticais como tempo, aspecto e modo verbais, e, também, adjetivos em posição predicativa.

Neves (1996) apresenta os diversos tipos de modalidade, entre elas a alética, epistêmica e deôntica. A modalidade alética, de acordo com Kiefer (1987 apud NEVES, 1996, p. 171), é centrada na lógica, ou seja, reflete uma escala lógica que vai do necessário ao impossível, passando pelo possível e contingente. Além disso, a escala reflete a capacidade (física, moral e intelectual) do locutor. Um enunciado alético é quase impossível de se manter descompromissado com a verdade, "é muito improvável, afinal, que um conteúdo asseverado num ato de fala seja portador de uma verdade não filtrada pelo conhecimento e pelo julgamento do falante" (NEVES, 1996, p. 171). Diferente da modalização alética, a modalidade epistêmica envolve o julgamento do falante sobre aquilo que seja provável que aconteça. 
Já a modalidade deôntica, objeto e foco de nossa pesquisa, está relacionada aos valores de obrigação e permissão, situada no domínio do dever. $\mathrm{Na}$ expressão da modalidade deôntica, é possível verificar que o interlocutor deve aceitar a verdade do enunciado para que este seja executado.

Na literatura linguística (LYONS, 1977), o termo deôntico tem origem na palavra grega deon (o que é obrigatório) e se refere à lógica da obrigação e da permissão. Ao definir a modalidade deôntica, Lyons (1977) relaciona algumas características. A primeira é relacionada à sentença, que nesse tipo de modalidade, não descreve um ato em si mesmo, mas um estado-de-coisas.

A modalização deôntica está situada no nível da predicação; ao expressar, então, o estatuto da realidade de um estado-de-coisas, o falante baseia sua avaliação no conhecimento de possíveis situações relativas a algum sistema de convenções morais, legais ou sociais. De acordo com Gonçalves, Souza, Casseb-Galvão (2008), os predicados de valor deôntico indicam que o estado-de-coisas descrito na sentença encaixada completiva é apresentado como uma necessidade, obrigação, permissão ou como uma proibição. Podem ainda expressar uma capacidade atribuída ao referente do sujeito da sentença matriz de realizar o estado-de-coisas descrito na completiva.

Castilho (2010, p. 363) segue a mesma linha de pensamento ao dizer que:

Os modalizadores deônticos predicam o conteúdo sentencial, que passa a ser entendido como um estado-de-coisas que precisa ocorrer obrigatoriamente. Nãoé mais o valor de verdade da sentença que está em jogo, como nas classes anteriores [epistêmicos asseverativos e epistêmicos dubitativos]. Esses modalizadores correspondem à função desiderativa da linguagem, donde a noção de futuridade que os acompanha.

O eixo da conduta situa-se no domínio do dever (obrigação e permissão) e pode corresponder a atos diretivos de fala, ligando-se ao imperativo, em que se espera que o falante induza o outro a agir de determinada forma. De acordo com Casimiro (2007), a análise da modalidade deôntica abarca um conjunto de regras sociais e morais préestabelecidas, a partir das quais, os valores de permissão, obrigação ou necessidade são estabelecidos pelo falante. Tais regras podem se manifestar em leis, cultura e hábitos de uma sociedade.

Almeida (1980) já havia pontuado que a obrigação é dividida em moral, material e lógica. A obrigação moral é aquela que se fundamenta nas leis sociais, no costume, no decoro, nos princípios da religião e do indivíduo, trata-se do dever civil, profissional, religioso etc. A obrigação material ocorre por necessidade física, fisiológica, de natureza material em geral. O caráter da obrigação tem um envolvimento passivo que corresponde a ser obrigado ou necessário ${ }^{5}$.

Dessa forma, em nossa pesquisa, consideramos como base de análise: (a) obrigação moral, interna, ditada pela consciência que compele o agente a completar a ação; (b) obrigação material, ditada por imposição externa, social, imposição das circunstâncias que compelem o agente a completar a ação; e (c) necessidade.

\footnotetext{
5 Almeida (1980) define a obrigação lógica como aquela que tem vínculo nas deduções do raciocínio e é regida pelas leis do pensamento.
} 


\section{A construção impessoal}

Nas bases da Linguística Cognitiva, Achard (1998), em sua análise sobre a língua francesa, afirma que "as construções impessoais são usadas para descrever construções em que o sujeito gramatical é o chamado pronome "fictício" il (francês) e 'it' (inglês)"6. O autor afirma, ainda, que as construções impessoais deônticas serão sempre seguidas por infinitivo ou subjuntivo.

Diferente dos usuários da língua portuguesa, falantes do inglês ou francês usam os pronomes it e $i l$ como apêndice obrigatório antes do verbo. Embora ocupem a posição de sujeito sintaticamente, semanticamente tais marcadores não retomam ou apontam qualquer elemento do texto. Assim, embora os falantes de língua portuguesa não utilizem esse apêndice, encontramos semelhanças semântico-discursivas entre as construções completivas do português e as construções, tanto do francês quanto do inglês, como nos exemplos (03) e (04): ${ }^{7}$

(03) Il est nécessaire de demander un passeport before traveling voyager à l'etranger

It is necessary to apply for a passport before traveling abroad'

(04) Il est impératif qu'elle revienne à l'heure

'It is imperative that she come back on time'

Percebemos que as construções impessoais, enquanto em algumas línguas ocorrem morfologicamente marcadas, em outras, não, como na Língua Portuguesa, em que não há um pronome marcando inicialmente a impessoalidade e sendo apêndice do verbo. Como Dias (2013b) observa:

Embora haja sujeito oracional expresso, o falante opta pela forma sintática unipessoal (estrutura predicadora em 3. ${ }^{a}$ pessoa do singular), que dá um matiz semântico impessoal à estrutura predicadora alçada à posição inicial da construção. Com este recurso, o falante pode fazer contraste entre a construção completiva impessoal e o entorno discursivo (1. ${ }^{\mathrm{a}}$ e $3 .^{a}$ pessoas do plural), minimizando a sua participação no evento, corrigindo para se descomprometer. (DIAS, 2013b, p. 08)

Além disso, Dias (2013b) verifica os recursos utilizados pelo falante para se descomprometer das informações veiculadas por ele, como por exemplo, contrastar as pessoas usadas no entorno discursivo, aplicando, então, a responsabilidade da ação da construção completiva subjetiva ao outro, ou seja, ele é capaz de usar $1^{\mathrm{a}}$ pessoa do singular/plural ou $3^{\text {a }}$ pessoa do plural no entorno discursivo, mas ao fazer uso da construção, ele modifica para $3^{\text {a }}$ do singular a fim de causar o distanciamento.

\footnotetext{
${ }^{6}$ Conforme original (ACHARD, 1998, p. 269): "The term impersonal constructions (henceforth IC) is used to describe constructions where the grammatical subject is the so-called dummy pronoun il 'it"'.

${ }^{7}$ Extraídos de Achard (1998).
} 


\section{Análise e resultados}

Nosso primeiro objetivo é apresentar as ocorrências divididas pelos graus de modalidade deôntica. Foram encontradas, nos corpora investigados, 86 ocorrências da construção completiva impessoal deôntica (é preciso), 47 ocorrências na Folha de São Paulo e 39 ocorrências no $O$ Globo, ambas nos meses de setembro e outubro de 2013. Observamos que a posição inicial da estrutura predicadora é sempre a escolhida pelos escritores, já que isso dá destaque e marca a sua atitude enquanto usuário, como Dias (2013a, p. 20) afirma que, ao ocupar a posição no início da sentença, o falante coloca uma grande carga semântica na oração matriz, tornando-a expressão dos seus anseios, crenças, das proibições em relação a si mesmo e em relação ao outro participante da atividade discursiva.

Apesar de serem dois jornais diferentes, ambos tiveram resultados equilibrados, o que nos leva a concluir que a seção "Opinião" é produtiva quanto aos usos da expressão analisada, conforme tabela 1, abaixo.

Tabela 1. Ocorrências dos valores deônticos

\begin{tabular}{cccccc}
\hline \multirow{2}{*}{$\begin{array}{c}\text { Escala de } \\
\text { modalidade } \\
\text { deôntica }\end{array}$} & \multicolumn{2}{c}{ Folha de São Paulo } & \multicolumn{2}{c}{ O Globo } & TOTAL \\
\cline { 2 - 5 } & Setembro/2013 & Outubro/2013 & Setembro/2013 & Outubro/2013 & \\
\hline $\begin{array}{c}\text { Obrigação } \\
\text { externa }\end{array}$ & 16 & 11 & 5 & 11 & 43 \\
$\begin{array}{c}\text { Obrigação } \\
\text { interna }\end{array}$ & 5 & 2 & 5 & 6 & 18 \\
Necessidade & 4 & 9 & 7 & 5 & 25 \\
\hline TOTAL & 25 & 22 & 17 & 22 & 86 \\
\hline
\end{tabular}

Considerando os valores totais das ocorrências dos graus de modalidade deôntica, segundo a tabela 1, observamos um maior uso de obrigação externa em relação aos demais graus, e, por outro lado, um menor uso de obrigação interna. Tais distinções de usos podem se justificar pela facilidade de manipular o outro sobre uma necessidade física ou de maneira material em geral. Uma manipulação através da obrigação, com base em costumes morais, é feita de maneira mais branda. É possível observar as distinções em $(05)$ e $(06)^{8}$ :

(05) O problema não é bem querer ser adotado, é impedir a adoção. Pois todos somos inescapavelmente adotados por alguma entidade - uma língua, uma ideologia, um momento histórico e uma coletividade, por exemplo. É impossível escapar da adoção porque ninguém entra neste teatro de horrores escolhendo livremente todos os seus papéis. [...] Como disse muito bem o antropólogo Roberto Kant de Lima, quando um pequeno grupo impede uma multidão de ir e vir, o direito de manifestação tem que se entendercom o direito de ir e vir o qual, por sua vez, também tem que se haver com outros direitos... O que não é fácil num país no qual os poderosos sempre tomam as decisões.

\footnotetext{
${ }^{8}$ Em nosso trabalho, destacaremos as construções impes soais deônticas, nos exemplos, us ando negrito nas orações matrizes e sublinhado nas orações completivas subjetivas.
} 
Na minha opinião (que não resolve nada) seria preciso retomar aquele bom senso primordial do dar, receber e retribuir que Marcel Mauss ensinou e que nós, ignorantes mas estufados na nossa santa arrogância individualista, esquecemos.

$($ O Globo - 11.09.13)

(06) Assim como o consumidor está aprendendo a usar a tecnologia a seu favor, o varejo também deve aproveitá-la em prol da satisfação do cliente, realizando as mudanças que ele vem demandando.

Por isso, não basta oferecer diferentes formatos de lojas, sejam físicas ou virtuais. $\boldsymbol{E}$ preciso investir na inteligência do negócio com o intuito de fomentar a sinergia e integração entre eles, criando soluções integradas. Essa é a demanda do consumidor, é o que ele espera e é o que exigirá dos varejistas. Cabe ao setor estar pronto para atendela.

$\left(\right.$ Folha de São Paulo - 20.09.13) ${ }^{10}$

Em ambos os exemplos, é possível observar a tentativa de manipulação dos autores, com base em todo o entorno discursivo. Em (05), no trecho destacado: "seria preciso" (oração matriz) + "retomar aquele bom senso primordial do dar, receber e retribuir" (oração completiva com função de sujeito sintático), temos o exercício de uma obrigação moral, interna, ditada pela consciência. Já em (06), como se vê no trecho " $E$ " preciso" (oração matriz) + "investir na inteligência do negócio" (oração completiva com função de sujeito sintático), temos a obrigação material, ditada por imposição externa e pelas circunstâncias.

Ao ler os exemplos, vemos que em (05) há a obrigação de maneira mais moderada, e o autor usa recursos como o verbo da matriz no futuro do pretérito, que dá a ideia de condição de um fato que poderia acontecer após um fato já passado. De acordo com Casimiro (2007, p. 65), "o emprego do futuro do pretérito, ao contrário do presente do indicativo, confere uma maior atenuação da expressão deôntica". Por se tratar de um assunto que exige cautela, ele ameniza o discurso, dizendo, inclusive, que sua opinião não resolve nada, para depois afirmar que precisamos retomar o bom senso da reciprocidade e, a seguir, faz uma crítica ao fato de nos esquecermos disso.

No exemplo (06), vê-se nitidamente a obrigação puramente material ao tratar de comércio e bens de consumo. São dicas para lojistas sobre a maneira como o consumidor se comporta nos dias atuais, ou seja, o consumidor tem uma necessidade maior em relação aos produtos dos lojistas. Além disso, vemos que há menos marcadores de opinião explícitos, além do verbo da matriz estar no presente do indicativo, um fato atual.

Ao apontarmos o valor deôntico indicando necessidade, verificamos que o número de ocorrências fica entre o número de ocorrências de obrigação externa e o número de ocorrências de obrigação interna. Segundo Guiraldelli et al. (2010), a expressão da necessidade indica uma forma atenuada de ordenar, ou seja, expressa uma ordem "fraca" a ser cumprida. Desta forma, tais características ficam claras a partir do contexto apresentado pelo autor, como observamos em (07).

\footnotetext{
9 <http://oglobo.globo.com/opiniao/filtro-eficiente-9857928>

10 <http://www1.folha.uol.com.br/opiniao/2013/09/1344977-eneas-pestana-o-desafio-de-estar-presenteonde-o-consumidor-quer.shtml>
} 
(07) Não se discute que a modernização dos sistemas seja umdos caminhos a serem trilhados, mas, por enquanto, a morosidade ainda é característica predominante na Justiça brasileira.

Basta ver que a taxa de congestionamento do judiciário permanece, há tempos, em torno de $70 \%$. Em outras palavras, anualmente, a cada 100 processos, apenas 30 são resolvidos. O número é ainda pior nas execuções fiscais: $89 \%$ dos casos não foram decididos em 2012. Seria injusto imaginar que o quadro desalentador resulte apenas da incúria do Poder Judiciário. Muito pode ser feito, sem dúvida, no intuito de melhorar a prestaçãojurisdicional, mas é preciso reconhecer que esforços sãonecessários de ambos os lados da porta dos tribunais - e não somente quando os processos já chegaram aos cortes.

$\left(\right.$ Folha de São Paulo - 20.10.13) ${ }^{11}$

Observa-se que ainda há a tentativa de influenciar o leitor, mas desta vez de maneira amortecida. O escritor argumenta que o problema maior do atraso de processos, até o momento, é a morosidade da justiça. A seguir, mostra-nos porcentagens para confirmar sua ideia, porém assegura que é possível que muito seja feito para melhorar o quadro atual, entretanto, é necessário que esse leitor ou qualquer outro cidadão reconheça que não é culpa de um lado específico. Como vemos, na construção retirada do exemplo: é preciso (oração matriz) + reconhecer que esforços são necessários de ambos os lados da porta dos tribunais (oração completiva com função de sujeito sintático), fica instituída uma necessidade e não uma obrigação, isto é, há a necessidade de um reconhecimento para que não haja um julgamento equivocado.

Percebemos que a relação da necessidade, muitas vezes ocorre por oposição de eventos, conforme já exemplificado acima em (07). Dessa forma, a construção matriz "é preciso", quando introduz uma oposição, pode ser reforçada com o uso da conjunção "mas" ou do advérbio "não". Foram encontradas 11 ocorrências com "mas" e 6 ocorrências com "não" em todo o corpus, porém expressando necessidade, temos 7 com "mas" e 4 com "não".

A partir dos números analisados, conta-se que, das 25 ocorrências com traço de necessidade, 10 tiveram a presença de partícula de negação/adversidade, o que nos leva a concluir que, assim como Neves (2010, p. 209) aponta, a presença da negação transferida para a oração matriz "é uma estratégia de defesa utilizada pelo falante para atenuar o conteúdo proposicional declarado no enunciado complemento, e para, de certa forma, direcionar a interpretação do ouvinte".

Após verificarmos os graus da modalidade deôntica, consideramos quais os tipos de verbos recorrentes na oração completiva e quais estabeleceram alguma relação com o valor modal expresso na oração.

Foram encontrados, nas 86 ocorrências selecionadas, 35 verbos dinâmicos (físicos), 26 dinâmicos (não-físicos), 2 dicendi (outros), 1 dicendi prototípico, 20 epistêmicos ou cognitivos e 2 implicativos ou causativos. Feita esta classificação, agora podemos relacionar os resultados dos graus de modalidade com os tipos de verbos, conforme tabela 2 .

11 <http://www1.folha.uol.com.br/opiniao/2013/10/1359360-editorial-deposito-judicial.shtml> 
Tabela 2. Correlação entre graus de modalidade e tipos de verbo

\begin{tabular}{|c|c|c|c|c|c|c|c|c|c|c|c|}
\hline & \multicolumn{3}{|c|}{ Obrigação externa } & \multicolumn{4}{|c|}{ Obrigação interna } & \multicolumn{4}{|c|}{ Necessidade } \\
\hline & $\begin{array}{l}\text { Din. } \\
\text { Físico }\end{array}$ & $\begin{array}{c}\text { Din. } \\
\text { Não } \\
\text { Físico }\end{array}$ & $\begin{array}{l}\text { Cognitivo } \\
\text { Epistêmico }\end{array}$ & $\begin{array}{l}\text { Din. } \\
\text { Físico }\end{array}$ & $\begin{array}{c}\text { Din. } \\
\text { Não } \\
\text { Físico }\end{array}$ & $\begin{array}{l}\text { Cognitivo } \\
\text { Epistêmico }\end{array}$ & $\begin{array}{c}\text { Implic. } \\
\text { Causativo }\end{array}$ & $\begin{array}{l}\text { Din. } \\
\text { Físico }\end{array}$ & $\begin{array}{c}\text { Din. } \\
\text { Não } \\
\text { Físico }\end{array}$ & $\begin{array}{l}\text { Cognitivo } \\
\text { Epistêmico }\end{array}$ & Dicendi \\
\hline $\begin{array}{c}\text { Folha de } \\
\text { São } \\
\text { Paulo }\end{array}$ & 16 & 10 & 1 & 2 & 0 & 5 & 0 & 2 & 2 & 7 & 2 \\
\hline O Globo & 10 & 5 & 1 & 0 & 4 & 5 & 2 & 5 & 5 & 1 & 1 \\
\hline TOT AL & 26 & 15 & 2 & 2 & 4 & 10 & 2 & 7 & 7 & 8 & 3 \\
\hline
\end{tabular}

É possível perceber que há predominância de verbos do tipo dinâmico (físico e não-físico) na expressão da obrigação externa, em contrapartida, na obrigação interna há um maior uso de verbos cognitivos ou epistêmicos.

Isso parece confirmar nossa hipótese de que a obrigação externa, por ser baseada na natureza material em geral, deve ocorrer predominantemente com verbos do tipo dinâmico já que "estes exprimem uma ação ou atividade. São acompanhados por um participante agente ou causativo, podendo haver, ou não, outro participante (afetado ou não), isto é, podendo haver, ou não, um processo envolvido" (NEVES, 2011, p. 26). São verbos que, em sua essência, carregam valores de ação, sendo eles físicos ou não, mas que expressam a obrigação baseada em situações ou circunstâncias externas, conforme em (08).

(08) Nem sempre o recurso à engenharia genética é condenado pelos ambientalistas. Setores menos radicais da militância ecológica costumam dizer que não são contrários "por princípio" ao cultivo de plantas transgênicas.

Enfatizaminvariavelmente, entretanto, que é preciso realizar mais testes científicos, para avaliar o possível impacto desses novos organismos sobre o ecossistema, antes de lançálos no mercado.

(Folha de São Paulo - 13.10.13) $^{12}$

Na obrigação interna, há a predominância de verbos epistêmicos ou cognitivos, pois, de acordo com Neves (2011, p. 31-32), tais tipos de verbos se incluem nos chamados verbos factivos, que são aqueles que têm a propriedade de implicar, por parte do falante, a pressuposição de que a oração completiva é verdadeira, logo, a atitude desse falante interfere na situação do discurso. Uma das suas principais características é a de que não indicam um evento qualquer, e, sim, um fato que precisa ser afirmado. Desta forma, a obrigação moral passa a ser fundamentada em leis sociais, costumes e na própria consciência. Ela apresenta predisposição para ocorrer com verbos desse tipo, visto que, para influenciar a crença do outro, é preciso impressionar sua mente, como vemos em (09).

(09) "Fui passando, passando, passandoe chegueina quinta série semsaberlernemescrever. Dai minha mãe me colocou na primeira série de novo, quando eu tinha 11 anos. " Essa é a trajetória da Tia Edna, que, mesmo sem abandonar os estudos ou ser reprovada, concluiu o ensino médio apenas aos 22 anos. Hoje, com 39, ela se dedica a dar aulas de reforço para crianças na periferia de São Paulo, a maioria não alfabetizada.

O problema vivido por tia Edna persiste. A sociedade brasileira ainda não solucionou a desigualdade que afeta, particularmente, territórios vulneráveis como as periferias

\footnotetext{
$12<$ http://www1.folha.uol.com.br/opiniao/2013/10/1355836-editorial-experimento-eleitoral.shtml>
} 
urbanas e as zonas rurais. É preciso reconhecer as desigualdades que marcamo acesso à língua escrita e às práticas de letramento no Brasil.

$$
\left(\text { Folha de São Paulo - 15.09.13) }{ }^{13}\right.
$$

A necessidade, novamente, situa-se com o número intermediário de ocorrências em relação à obrigação externa e interna, tendo verbos tanto dinâmicos quanto epistêmicos ou cognitivos. Diferente dos demais graus, apresenta, ainda, ocorrências com verbos do tipo dicendi. Por se manter entre os dois tipos de obrigação, esperava-se que os números de ocorrência para os tipos de verbo também fossem intermediários, uma vez que, tanto verbos dinâmicos, quanto epistêmicos/cognitivos podem ser usados para expressar uma necessidade.

Quanto aos verbos do tipo dicendi, Neves (2011, p. 48) afirma que "são verbos de elocução propriamente ditos - são verbos de ação cujo complemento direto é o conteúdo do que se diz". Além disso, há também outros tipos de verbos que são usados para expressar a elocução sem ser os habituais "falar" e "dizer". A hipótese formulada é a de que obrigar o outro a falar algo é uma imposição que deixa de ser mascarada, sendo assim, é necessário que se amenize o discurso para que haja tal exigência, como é possível perceber em (10).

(10) “A superação da onda de violência em 2012 só foi possivel porque houve trabalho. É o caso da revisão de procedimentos operacionais por parte da Polícia Militar. Na perseguição a criminosos, por exemplo, passou-se a dar prioridade à negociação e prisão, evitando-se o confronto.

Outra medida foi a resolução $n^{\circ} 5$, de janeiro. Ela determina que, como acontece com vítimas de acidentes de trânsito, pessoas baleadas sejam socorridas por resgate especializado, o que tem salvado vidas. Em paralelo, com a cena do crime preservada, as investigações estão mais eficientes, o que contribui para a redução de mortes.

Quanto aos roubos, é preciso dizer que há, sim, necessidade de reforma le gislativa. Não é possivel que um ladrão que usa dinamite para furtar um caixa eletrônico esteja sujeito às mesmas penas daquele que pula ummuro para surrupiarumbotijãode gás. É preciso, igualmente, rever os critérios da progressão penal.

(Folha de São Paulo - 10.10.13) $)^{14}$

Mesmo sem a presença da conjunção "mas", o autor expressa uma relação adversativa com o que o foi dito anteriormente. Há a necessidade de uma reforma legislativa, mas é necessário que haja o reconhecimento das informações por parte de quem o lê. Trata-se de um texto inteiramente modalizado, com ocorrência da construção "é possível" indicando a modalidade epistêmica, e, após, mais uma ocorrência com "é preciso" indicando necessidade.

Quanto aos aspectos do matiz impessoal, das 86 ocorrências, houve um contraste com o entorno discursivo em 62, sendo 20 do jornal $O$ Globo e 42 da Folha de São Paulo. Nesses casos, em que há o contraste com o intuito de se distanciar da informação veiculada, temos a alternância das marcas de desinências número/pessoa dos verbos (destacados em negrito, anteriores à oração matriz) em relação à construção é preciso. Podemos observar a atenuação de tais características nos exemplos (11) e (12):

\footnotetext{
$13<$ http://www1.folha.uol.com.br/opiniao/2013/09/1342215-maria-a lice-setubal---o-direito-aoletramento.shtml $>$

14 <http://oglobo.globo.com/opiniao/a-revisao-populacional-do-ibge-10342791〉
} 
(11) Confesso que considero as manifestações radicais contra mudanças da Previdência, feitas em nome de um posicionamento ideológico, expressões que se situam entre a ignorância e o delírio. É claro que compreendo por que as pessoas se opõem a trabalhar por um maior número de anos - não é preciso ser um luminar para entender por que se trata de uma temática impopular.

$(O \text { Globo }-14.10 .13)^{15}$

(12) Não basta, entretanto, promover tal mudança se os torneios continuarem a se atropelar, exigindo em demasia dos jogadores dos principais clubes. $\dot{E}$ preciso equacionar o calendário de modo a reservar datas para competições nacionais e internacionais sem a realização de jogos em um curto período de tempo.

$\left(\right.$ Folha de São Paulo - 06.10.2013) ${ }^{16}$

É possível confirmar que, em Língua Portuguesa, não há o uso do pronome impessoal, e o sujeito da oração matriz é preciso, é oracional, conforme em (11) e (12), ambos reduzidos de infinitivo. Semanticamente temos o matiz impessoal, como Dias (2013) aponta, quando há o contraste, utilizado pelo falante, com o intuito de se descomprometer da informação apresentada na oração completiva. Dessa forma, o falante utiliza, no discurso, a $3^{\text {a }}$ pessoa do plural e, ao acrescentar seu ponto de vista do que deveria ser feito acerca de determinado evento, ele inicia com a $3^{\text {a }}$ pessoa do singular, modalizando então o seu discurso. Observemos agora os próximos exemplos, em (13) e (14), que asseguram essa hipótese.

(13) Eu afirmo que não se pode ter democracia com um comportamento permanentemente dúbio. [...] Mesmo admitindo que o sistema liberal deixa muito a desejar, convenhamos que é preciso ter bons atores para levar à frente um teatro democrático que requer senso de limite, consciência dos papéis e um mínimo de honra.

$(\text { O Globo }-04.09 .2013)^{17}$

(14) A biografia escrita sobre mim é um bom exemplo para o debate em questão. [...] Em nenhum momento cogitei proibir sua publicação porque acredito e aposto na liberdade de expressão em regime democrático. [...] Mas é preciso garantir tanto a liberdade de expressão quanto a reparação em caso de ofensa. Deve-se garantir plena isonomia entre o direito de publicar biografias e o direito de resposta e proteção à honra.

$\left(\right.$ Folha de São Paulo - 30.10.2013) ${ }^{18}$

Em ambos os exemplos (13) e (14), notamos o distanciamento dado pelos autores ao fazerem uso da $3^{\text {a }}$ pessoa do singular para se distanciarem do que foi dito, destacado em negrito.

No exemplo (13), vemos a afirmação categórica do autor sobre o fato de a dubiedade de comportamentos ser ruim para a democracia, além disso, admite que o sistema liberal deixa a desejar, pede para que o leitor concorde com ele e, em seguida, introduz a construção completiva impessoal, mostrando que é obrigatório ter bons atores

\footnotetext{
15 <http://oglobo.globo.com/opiniao/voces -pensam-que-moleza-10259345>

$16<\mathrm{http}$ //www1.folha.uol.com.br/opiniao/2013/10/1352440-editorial-bom-senso-no-futebol.shtml>

$17<\mathrm{http} / / /$ oglobo.globo.com/opiniao/somos -a-prova-de-palavra-9811166>

18 <http://www1.folha.uol.com.br/opinião/2013/10/1364092-jose-dirceu-entre-tapas-e-beijos.shtml>
} 
para continuar com um teatro desse tipo. Ainda que "atores" seja usado no sentido metafórico, ele deixa claro que alguém deve coordenar a desordem instaurada.

Já em (14), temos, em negrito, o autor escrevendo todo o texto na $1^{\mathrm{a}}$ pessoa do singular, fazendo afirmações sobre a liberdade de expressão, mas, ao inserir a construção impessoal, atribui ao outro a obrigação de garantir essa liberdade. Não deixa claro quem deve fazer, mas explica que é preciso garantir plena isonomia entre o direito de publicar biografias e o direito de resposta, bem como a proteção à honra.

\section{Considerações finais}

O objetivo deste trabalho foi investigar a construção completiva impessoal constituída de oração matriz com verbo ser + predicativo preciso, seguida de uma oração completiva com função de sujeito sintático, considerando os graus da construção que variam entre obrigação externa, obrigação interna e necessidade, conforme proposto por Almeida (1980) e Neves (1996).

Com base nos estudos empreendidos por Dias (2013a, 2013b), acreditamos que os valores semântico-discursivos desses graus dizem respeito às marcas de (inter) subjetividade que o falante emprega no discurso. Sobre o assunto, Dias (2013a, p. 84) aponta que "o falante coloca o seu posicionamento, a sua atitude diante de uma situação discursiva e poderá tentar trazer o ouvinte para compartilhar a situação".

Antes de destacarmos quais as contribuições dos resultados alcançados, é importante retomar as definições dos graus da modalidade deôntica, em que os valores de obrigação são variáveis, desde uma obrigação que é expressa internamente, baseada em valores da consciência, até a externa, que é baseada no material ou nas circunstâncias em geral; e ainda a necessidade que expressa uma obrigação de maneira branda, acontecendo, principalmente, em contraposição de ideias ou eventos, assim como Neves (2010) já havia afirmado.

Em relação aos resultados, após oferecermos um quadro de ocorrências dos graus de modalidade deôntica nos corpora investigados, percebemos que houve predominância de construções indicando a obrigação material, seguida do número de ocorrências de necessidade, e a obrigação interna ligada à consciência esteve em menor número. As razões para tal acontecimento seriam a facilidade para manipular o outro sobre algo físico ou material, já que uma manipulação baseada nos costumes deve ser feita de maneira breve e com muito cuidado para que não haja más interpretações. A necessidade ainda expressa que o outro deva fazer alguma coisa, mas sempre de maneira velada, pois se trata de uma ordem fraca a ser cumprida.

Também é possível perceber que os graus da modalidade deôntica apresentam uma relação com o tipo de verbo utilizado na oração encaixada completiva com função de sujeito sintático, pois encontramos uma maior predominância de verbos dinâmicos na obrigação externa, por expressarem ações; verbos cognitivos ou epistêmicos na obrigação interna, por serem verbos que indicam um fato que precisa ser afirmado; e a necessidade revelou número de ocorrências dos tipos de verbo entre as duas obrigações, indicando, então, que, por se tratar de uma ordem amenizada, pode ocorrer com verbos de qualquer tipo. 
Quanto ao matiz impessoal atribuído à construção completiva, decorrente do contraste feito entre a oração matriz, sempre na $3^{\text {a }}$ pessoa do singular, e o entorno argumentativo, que pode variar entre $1^{a}$ pessoa do singular/plural e $3^{a}$ pessoa do plural, tal recurso utilizado pelo falante é característico da necessidade de impor algo para o outro, sem se comprometer. Isso confirma a hipótese apresentada por Dias (2013b) de que há todo um recurso externo utilizado (baseado em dados, porcentagens, opiniões gerais) para a ordem ser dada, com o uso da oração matriz a impessoalizar o que deve ser dito.

A modalidade deôntica possibilita que o falante estabeleça a obrigação, a necessidade, a permissão ou a proibição, mas, em nossos corpora, foram encontrados valores apenas de obrigação e necessidade. Através desses graus de modalidade, parece que os recursos que o falante utiliza, tanto para influenciar o outro, quanto para se descomprometer, fazem parte de estratégias discursivas para convencer alguém do seu ponto de vista. Além disso, tais avaliações feitas e colocadas na oração matriz, em posição inicial, revelam a marca do distanciamento do locutor, bem como o seu descomprometimento com o que é transmitido.

\section{REFERÊNCIAS}

ACHARD, M. Representation of cognitive structures: syntax and semantics of French sentential complements. Berlin: Mouton de Gruyter, 1998. 377 p.

ALMEIDA, J. Introdução ao estudo das perífrases verbais em português. s. 1., s. ed., 1980. $241 \mathrm{p}$.

CASIMIRO, S. Um estudo das modalidades deôntica e volitiva nos discursos do presidente Lula. 2007. 107 f. Dissertação (Mestrado em Estudos Linguísticos) - Instituto de Biociências, Letras e Ciências Exatas, Universidade Estadual Paulista, São José do Rio Preto.

CASTILHO, A. T. de. Nova gramática do português brasileiro. São Paulo: Contexto, 2010. $768 \mathrm{p}$.

CUNHA, M. A. F.; TAVARES, M. A. Linguística funcional e ensino de gramática. In: CUNHA, M. A. F.; TAVARES, M. A. Funcionalismo e ensino de gramática. Natal: Editora da UFRN, 2007. p. 13-51.

CUNHA, M. A. F.; BISPO, E. B.; SILVA, J. R. Linguística funcional centrada no uso: conceitos básicos e categorias analíticas. In: CEZARIO, M. M.; CUNHA, M. A. F. Linguística centrada no uso: uma homenagem a Mário Martelotta. Rio de Janeiro: Mauad X: FAPERJ, 2013. p. 13-39.

DIAS, N. B. A marca da (inter) subjetividade na sentença complexa subjetiva. Revista Confluência, Rio de Janeiro, n.44, p. 83-106, 2013a.

. A subjetividade nas construções completivas impessoais do português brasileiro. Revista Portuguesa de Humanidades, Braga, v.17, n.1, p. 7-22, 2013b.

GIVÓN, T. On understanding grammar. New York: Academic Press, 1979. 379 p.

GONÇALVES, S. C. L.; SOUSA, G. C. de; CASSEB-GALVÃO, V. C. As construções subordinadas substantivas. In.: ILARI, R.; NEVES, M. H. M. Gramática do português 
culto falado no Brasil. v. 2. Classe de palavras e processos de construção. Campinas: Editora da UNICAMP, 2008. p. 1021-1084.

GUIRALDELli, L. A.; SANTOS, A. C. O. dos. A modalidade deôntica nas bulas de remédio. Revista Nucleus, Ituverava, v.7, n.2, p. 47-64, out. 2010.

LYONS, J. Semantics: Front Cover. Cambridge: Cambridge University Press, 1977. 897 p.

NEVES, M. H. M. A modalidade. In: KOCH, I. (Org.) Gramática do português faladov.vi: Desenvolvimentos. Campinas: FAPESP/UNICAMP, 1996. p. 163-199. . Texto e gramática. São Paulo: Contexto, 2010. 334 p. . Gramática de usos do português. São Paulo: Editora UNESP, 2011. 103 p.

SILVA, A. S. Linguística Cognitiva. Uma breve introdução a um novo paradigma em Linguística. Revista Portuguesa de Humanidades, Braga, v.1, n.1, p. 59-101, 1997.

Recebido em: 05/10/2015

Aprovado em: 15/03/2016 